\title{
Meconium Peritonitis
}

National Cancer Institute

\section{Source}

National Cancer Institute. Meconium Peritonitis. NCI Thesaurus. Code C102977.

Inflammation of the peritoneum caused by an intrauterine intestinal perforation leading to presence of meconium within the fetal peritoneal cavity. This is frequently seen as intra-abdominal calcifications on imaging. 